\title{
Design of experiments for non-manufacturing processes: benefits, challenges and some examples
}

J Antony $^{1 *}$, S Coleman ${ }^{2}$, D C Montgomery ${ }^{3}$, M J Anderson ${ }^{4}$, and R T Silvestrini ${ }^{5}$

${ }^{1}$ Centre for Research in Six Sigma and Process Excellence (CRISSPE), Strathclyde Institute for Operations Management, Department of DMEM, University of Strathclyde, Glasgow, UK

${ }^{2}$ Industrial Statistics Research Unit, Newcastle University, UK

${ }^{3}$ School of Computing, Informatics and Decision Systems Engineering, Ira A. Fulton School of Engineering, Arizona State University, Tempe, Arizona, USA

${ }^{4}$ Stat-Ease, Inc., Minneapolis, Minnesota, USA

${ }^{5}$ Department of Operations Research, Naval Postgraduate School, Monterey, California, USA

The manuscript was received on 16 July 2010 and was accepted after revision for publication on 7 December 2010.

DOI: $10.1177 / 0954405411395857$

\begin{abstract}
Design of Experiments (DoE) is a powerful technique for process optimization that has been widely deployed in almost all types of manufacturing processes and is used extensively in product and process design and development. There have not been as many efforts to apply powerful quality improvement techniques such as DoE to improve non-manufacturing processes. Factor levels often involve changing the way people work and so have to be handled carefully. It is even more important to get everyone working as a team. This paper explores the benefits and challenges in the application of DoE in non-manufacturing contexts. The viewpoints regarding the benefits and challenges of DoE in the non-manufacturing arena are gathered from a number of leading academics and practitioners in the field. The paper also makes an attempt to demystify the fact that DoE is not just applicable to manufacturing industries; rather it is equally applicable to non-manufacturing processes within manufacturing companies. The last part of the paper illustrates some case examples showing the power of the technique in non-manufacturing environments.
\end{abstract}

Keywords: Design of Experiments (DoE), process optimization, non-manufacturing processes, product and process design and development

\section{INTRODUCTION}

Design of Experiments (DoE), sometimes called multifactor testing (MFT), is fundamental and crucial to increase the understanding of a product or process.

*Corresponding author: Centre for Research in Six Sigma and Process Excellence (CRISSPE), Strathclyde Institute for Operations Management, Department of DMEM, University of Strathclyde, Glasgow G1 1XJ, Scotland, UK.

email: jiju.antony@strath.ac.uk
It provides a powerful means to achieve breakthrough improvements in product quality and process efficiency. According to Montgomery [1], DoE is a powerful tool that enables the effects of several system or process variables to be investigated simultaneously and efficiently, leading to an increased understanding of the system. DoE is a direct replacement of the traditional one-factor-at-a-time (OFAT) or 'hit or miss' approach to experimentation and the sequential testing approach of Shainin (see Antony [2] and Shainin and Shainin [3]). 
DoE has been widely applied to various problems in the manufacturing arena, but little attention has been paid to its applications in the context of non-manufacturing. Although it has been around for decades, few business leaders in service organizations have a good grasp of its power in tackling problems associated with service process efficiency and effectiveness (see Johnson and Bell [4]). This field remains fertile ground for greater education, experience, and application. Service-oriented industries such as financial services, transportation services, hotel and restaurant services, healthcare industry, utility services, IT services, etc., are the fastest growing sectors around the world (see Kapadia and Krishnamoorthy [5]). Customers are becoming more critical of the service they receive today and therefore most modern organizations are paying more attention to their transactional service processes.

The present research has clearly indicated that relatively few applications of DoE in a non-manufacturing environment have appeared in the academic literature (see Ledolter and Swersey [6], Blosch and Antony [7], and Kumar et al. [8]). This paper presents the benefits of DoE in non-manufacturing settings, the fundamental challenges encountered by practitioners in the application of DoE in non-manufacturing processes, and provides examples that demonstrate the power of DoE in non-manufacturing settings.

\section{DESIGN OF EXPERIMENTS IN NON-MANUFACTURING INDUSTRY: FUNDAMENTAL CHALLENGES}

A product realization process initiated by the manufacturer usually begins with product design and development, a set of product specifications, process development, then production and testing, and concludes with delivery to the customer. If at any point in the process products do not meet specifications, they can either be scrapped or reworked. Non-manufacturing or service processes, on the other hand, generate value as the customer interacts with the process and, ultimately, it is the customers' experience with the process that is most important. The distinction between the process, the delivery of the process, and the customers' responses is often difficult to define. The exact sequence of activities in a non-manufacturing or service process is often difficult to predict in advance.

There are a number of reasons why DoE has not been commonly employed in non-manufacturing or service settings. Some of the most fundamental barriers and challenges in applying DoE in a service environment are highlighted below. For more discussion, see Roes and Dorr [9], Raajpoot et al. [10], Holcomb [11], Kumar et al. [8], Johnson and Bell [4], and Blosch and Antony [7].

- Lack of awareness, knowledge and misconceptions discourage experimentation in many service organizations.

- The performance of a service process is very difficult to measure accurately.

- Service process performance depends a great deal on the behaviour of the human beings involved in delivering it.

- Service processes have more 'noise' factors associated with them (queuing, friendliness, location, politeness, etc.).

- As service is often simultaneously created and consumed and intangible dimensions are important indicators of quality on service context, experimental control of inputs and measurement of output requires careful consideration.

- In any service process, a clear description and distinction of service processes is needed for quality control and improvement. A good understanding of front office, back office, and customer processes is required for quality and process improvements.

Table 1 was generated from a recent study carried out by the first author. A number of experts in the field of DoE (both academics and practitioners) were approached by the first author and the responses were collected over a period of two weeks. Each respondent was approached with a question: 'What are the fundamental challenges in the application of DoE in the non-manufacturing or service sector?'

The key question to be asked is: 'What do we need to do to encourage more applications of DoE in the non-manufacturing industry?' Owing to the increasing applications of Six Sigma in both service and transactional processes, in particular, the finance, hotel, billing, invoicing, administrative processes, and health sectors, more applications of DoE are likely to be seen in the improve phase of Six Sigma methodology. In the context of service, quality, speed, and cost are quite critical just as they are in manufacturing. Design of Experiments is a very powerful technique that can be employed by many nonmanufacturing or service organizations to achieve a good balance between quality (i.e. improvement of service and product quality) and cost (i.e. reduction of operational costs), but also increase the speed with which the balance can be achieved. Table 2 shows how Six Sigma initiatives in the service sector can influence the deployment of DoE. 
Table 1 Challenges in the application of DoE in non-manufacturing or service settings

Respondents and their affiliations

Kai Yang, Wayne State University, USA

Phil Rowe, Consultant and Six Sigma Master Black Belt, Bourton Group, UK

Mark Anderson, Principal and General Manager, Stat-Ease, USA

Larry Smith, Independent consultant, USA

Sung Park, Seoul University, South Korea

Ronald Snee, Consultant, Tunnell Consulting, USA

Alessandro Laureani, Master Black Belt, Hertz Services, Ireland

Roger Hoerl, General Electric, USA

Challenges

- Cannot do too many trials of controlled tests in a service environment

- People in the service sector are by and large not used to using/dealing with databased decision-making

- DoE is a 'techy' tool; managers in the service sector may be less likely to have a mathematical background and be perhaps more likely (than in engineering, say) to be driven by 'experience' and 'gut feeling' - wanting to be seen to be incisive and intuitive

- Choosing the right response variables and dealing with subjectivity within the experimental regime

- The involvement of people. Whereas a machine can be subjected to change with no trouble (provided its operating constraints are not exceeded), humans resist new approaches to doing things

- The biggest challenge is in determining what to measure and in finding operational control factors to conduct the DoE. It is also effective if a service process can be computer simulated so that the DoE may be done as a simulation

- The fundamental challenges are that it is not easy to obtain the necessary observed data in the service sector, and also it is not easy to provide the same experimental condition for repeated measurement in the service sector

- Lack of standardized work processes

- Lack of improvement mindset

- Greater amount of human intervention

- Can be more difficult to administer the design properly and get quality data

- As human factors are an important factor, randomization is necessary in the context of service

- As there is an intangible component with the delivery of service, results may not be as reliable as manufacturing

- Careful selection of factor levels is required due to involvement of people and the interaction between the customer and service provider

- Personally, I think the cultural issues are greater. For one, there is rarely a culture of using the scientific method or applying continuous improvement in most service organizations

- Persuade people to follow a systematic methodology for process improvement and to convince them to rely on the power of data to drive the decision-making process

Table 2 The influence of Six Sigma initiatives in the non-manufacturing or service sector on deployment of DoE (adapted from Goh [12])

\begin{tabular}{|c|c|c|}
\hline Aspect & Past & Future \\
\hline Impetus & Operational level & Top management \\
\hline Training provision & Stand-alone courses & $\begin{array}{l}\text { Structured company-wide programmes such } \\
\text { as Six Sigma }\end{array}$ \\
\hline Motivation of experimentation & Technical performance & $\begin{array}{l}\text { Improved sales and enhanced customer } \\
\text { satisfaction }\end{array}$ \\
\hline Success criterion & Engineering objectives & Impact on the bottom-line in hard cash savings \\
\hline Project ownership & $\begin{array}{l}\text { Isolated individuals (industry statisticians, } \\
\text { external consultants) }\end{array}$ & Multidisciplinary teams across the business \\
\hline Focus of application & Primarily manufacturing processes & $\begin{array}{l}\text { Service, transactional and now governance } \\
\text { processes }\end{array}$ \\
\hline Project selection & $\begin{array}{l}\text { Primarily projects are related to single functional } \\
\text { problems }\end{array}$ & $\begin{array}{l}\text { Projects are related to cross-functional } \\
\text { problems }\end{array}$ \\
\hline
\end{tabular}

\section{BENEFITS OF DoE IN}

NON-MANUFACTURING/SERVICE

INDUSTRY: A REVIEW OF THE LITERATURE AND SOME KEY FINDINGS

The purpose of this section is to illustrate the benefits of DoE in various non-manufacturing/service settings. Our search for service applications of DoE has found a few papers in the marketing and service/ retail industry literature. Holland and Cravens [13] presented the essential features of fractional factorial design and illustrated a very interesting example looking into the effect of advertising and other critical factors on the sales of candy bars. Ledolter and Swersey [6] described the power of a fractional 
factorial experiment to increase the subscriptions response rate of Mother Jones magazine. Kumar et al. [8] used a Taguchi robust parameter design methodology in order to improve the response-time performance of an information group operation that was responsible for addressing customer complaints concerning a small software export company. Holcomb [11] illustrated the use of Taguchi parameter design methodology to determine the optimal settings of customer service delivery attributes that reduce cost without affecting quality. Blosch and Antony [7] demonstrated the use of computer simulation and DoE to identify the key risk variables within the manpower planning system at the UK's Royal Navy. This combined approach has provided a greater understanding of the manpower planning system, especially in terms of reducing gapping (a gap occurs when a particular job or task is not being filled by a competent and qualified person) at sea. Starkey [14] used a Plackett-Burman design in designing an effective direct response TV advertisement. Raajpoot et al. [10] presented the application of Taguchi approach of DoE to retail service. The study was performed by undergraduate students at a midsize university in the USA to determine the key attributes of shopping experience in a superstore setting such as Wal-Mart or Target. Anderson [15] has compiled a number of excellent examples. The potential applications of DoE in the non-manufacturing/ service environment include:

- identifying the key service process or system variables that influence the process or system performance;

- identifying the service design parameters that influence the service quality characteristics or CTQs in the eyes of customers;

- minimizing the time to respond to customer complaints;

- minimizing errors on service orders;

- reducing the service delivery time to customers (e.g. banks, restaurants, etc.);

- reducing the turn-around time in producing reports to patients in a healthcare environment, and so on.

Table 3 presents the potential benefits obtained from the applications of DoE in a service setting. The table was generated from a questionnaire developed by the first author and the responses from each respondent are incorporated in the table.

Table 4 shows the real benefits of DoE in the context of non-manufacturing/service. The table is generated from a review of various case studies and examples from periodicals, textbooks, websites,

Table 3 Potential benefits of DoE in non-manufacturing/service industries

\begin{tabular}{|c|c|}
\hline Respondents and their affiliations & Benefits \\
\hline Kai Yang, Wayne State University, USA & $\begin{array}{l}\text { - To evaluate the cause-effect relationship between a set of service process vari- } \\
\text { ables and service performance characteristics }\end{array}$ \\
\hline $\begin{array}{l}\text { Phil Rowe, Consultant and Six Sigma Master Black } \\
\text { Belt, Bourton Group, UK }\end{array}$ & $\begin{array}{l}\text { - It promotes a scientific approach to understanding service business processes } \\
\text { and customer behaviours - it changes a culture from gut feelings to fact-based } \\
\text { - It reveals interactions that would never be understood otherwise }\end{array}$ \\
\hline Mark Anderson, Stat-Ease, USA & $\begin{array}{l}\text { - Reduce cost of quality due to rework and misinformation that led to bad decision } \\
\text { making }\end{array}$ \\
\hline Sung Park, Seoul University, South Korea & $\begin{array}{l}\text { - Since service organizations also seek customer satisfaction, variation reduction, } \\
\text { quality improvement and reduction of COPQ, DoE can provide a solution among } \\
\text { many possible alternatives }\end{array}$ \\
\hline $\begin{array}{l}\text { Ronald Snee, Consultant, Tunnell Consulting, } \\
\text { USA }\end{array}$ & $\begin{array}{l}\text { - Is systematic } \\
\text { - Is efficient and low cost } \\
\text { - Can estimate the effects of interactions } \\
\text { characteristics }\end{array}$ \\
\hline Matthew Hu, Consultant and MBB, USA & $\begin{array}{l}\text { - DoE is a good tool to help service organizations to quantify and understand the } \\
\text { important process variables that cause variation so that the processes can be } \\
\text { improved }\end{array}$ \\
\hline Alessandro Laureani, MBB, Hertz Services, Ireland & $\begin{array}{l}\text { - To identify interactions between factors or process parameters in a service } \\
\text { process that influence the service output(s) }\end{array}$ \\
\hline $\begin{array}{l}\text { Ronald Does, University of Amsterdam, The } \\
\text { Netherlands }\end{array}$ & $\begin{array}{l}\text { - DoE is a powerful tool also in service organizations to establish relationships } \\
\text { between the CTQ and the most important influence factors }\end{array}$ \\
\hline Roger Hoerl, General Electric, USA & $\begin{array}{l}\text { - Able to get better information and clearer understandings of cause-and-effect } \\
\text { relationships, and to do so cheaper and easier than any other method } \\
\text { - There is the additional advantage in service that very few of your competitors will } \\
\text { be using this approach, unlike the situation in manufacturing and engineering. } \\
\text { Therefore it is one way of getting clear competitive advantage }\end{array}$ \\
\hline
\end{tabular}


and white papers. The case studies represent a broader range of services from administration, customer service, financial services, and healthcare settings.

\section{USE OF COMPUTER MODELS}

One of the difficulties in applying designed experiments in service and transactional businesses is that it is often difficult or impossible to experiment physically with the system under study. For example, suppose that there is a need to improve service operations in a hospital emergency department (ED). The response variable may be the patient waiting time and there may be several factors that could be considered as factors in a designed experiment, including varying the number of personnel on duty, the mix of skills in the on-duty personnel, the number of treatment rooms, the types of treatment and diagnostic equipment available, the physical layout of the $\mathrm{ED}$, and the sequencing procedure that determines the order in which arriving patients are processed.
Clearly some of these factors should have an effect on patient throughput and hence waiting times. However, varying these factors in a designed experiment would be impractical, and in most instances impossible. This situation is encountered in many improvement projects involving service and transactional operations. The Winter Simulation Conference held in December each year has a health care track that includes many instances of simulation models of hospitals and health care systems. For examples of ED simulations that involve experimental design see Garcia et al. [16], Miller et al. [17], and Simon and Armel [18]. Later in the paper, a case study is presented. The remainder of this section details the approach of experiments on computer simulation and some unique experimental design challenges.

The usual approach in these situations is to build a computer model of the process and then apply designed experiments to the model. If the model is built properly and validated, then results from the experiment conducted on the model can be transferred to the actual process.

Table 4 Real benefits of DoE in non-manufacturing/service processes

\begin{tabular}{|c|c|c|}
\hline Area & Design & Benefits achieved \\
\hline $\begin{array}{l}\text { Bill processing in a utility } \\
\text { company }\end{array}$ & $\begin{array}{l}\text { A one-way randomized ANOVA design with } \\
\text { three experimental treatments was } \\
\text { selected }\end{array}$ & $\begin{array}{l}\text { - Reduction of } 70 \% \text { in the number of hours taken to pro- } \\
\text { cess bills without incurring capital cost or increasing any } \\
\text { human resource } \\
\text { - Savings generated from the project were estimated to be } \\
\text { well over } \$ 100000 \text { US per annum } \\
\text { - Better understanding and a greater insight into how } \\
\text { process works }\end{array}$ \\
\hline Account receivables & $\begin{array}{l}8 \text { trial fractional factorial design was per- } \\
\text { formed to study four factors at two levels }\end{array}$ & $\begin{array}{l}\text { - The receivables age can be reduced from the current } \\
\text { average of } 200 \text { days to } 44 \text { days } \\
\text { - Improvement in the cash flow in the company }\end{array}$ \\
\hline $\begin{array}{l}\text { Manpower planning in Royal } \\
\text { Navy }\end{array}$ & $\begin{array}{l}27 \text { trial full factorial experiment (simula- } \\
\text { tion) was performed to study three risk } \\
\text { variables within the manpower planning } \\
\text { system }\end{array}$ & $\begin{array}{l}\text { - Identified the optimal condition of risk variables that } \\
\text { reduces the existing gapping at sea } \\
\text { - } 40 \% \text { improvement over the current gapping at sea }\end{array}$ \\
\hline $\begin{array}{l}\text { Computer downtime in a small } \\
\text { export company }\end{array}$ & $\begin{array}{l}18 \text { trial Taguchi orthogonal array experi- } \\
\text { ment was performed to study eight fac- } \\
\text { tors at three levels }\end{array}$ & $\begin{array}{l}\text { - Improved the system response time by over } 10 \% \\
\text { Increased awareness of the use of more scientific } \\
\text { approach to understand the system among many senior } \\
\text { managers in the company }\end{array}$ \\
\hline Response rate for a web retailer & $\begin{array}{l}16 \text { trial fractional factorial experiment was } \\
\text { carried out to study five factors at two levels }\end{array}$ & - The response rate was improved by $75 \%$ \\
\hline Billing process & $\begin{array}{l}\text { Two level factorial experiment, studied over } \\
\text { a dozen factors at two levels }\end{array}$ & $\begin{array}{l}\text { - Savings of } \$ 2 \text { million in postage } \\
\text { - Developed a better telephone bill }\end{array}$ \\
\hline IT services & $\begin{array}{l}\text { A full factorial experiment was executed to } \\
\text { study three factors at two levels }\end{array}$ & $\begin{array}{l}\text { - The company did not have to replace and upgrade the } \\
\text { existing server, thus avoid an expense of nearly } \$ 50,000\end{array}$ \\
\hline Hospital & $\begin{array}{l}12 \text { trial Taguchi orthogonal array experi- } \\
\text { ment was performed to study } 11 \text { factors } \\
\text { at two levels }\end{array}$ & $\begin{array}{l}\text { - Length of Stay (LOS) in Emergency Dept has been } \\
\text { reduced from } 100 \text { minutes to } 80 \text { minutes } \\
\text { - Cost savings was estimated to be well over } \$ 50,000\end{array}$ \\
\hline Financial services & $\begin{array}{l}16 \text { trial fractional factorial design was } \\
\text { selected to study five factors at two levels }\end{array}$ & $\begin{array}{l}\text { - Reduced rework rate due to incomplete information } \\
\text { provided by the customer } \\
\text { - Increased application completeness from } 60 \text { to } 95 \% \\
\text { - Reduced cycle time for the loan and lease application } \\
\text { process }\end{array}$ \\
\hline
\end{tabular}


Broadly speaking, there are two types of computer models used in improvement activities, discreteevent simulation models and deterministic models. Discrete-event simulation models are usually transaction-based and driven by random components that are modelled by probability distributions. For example, in the hospital emergency department application, the number of patients (or transactions) that arrive per hour may be modelled by a Poisson distribution whose mean is time-dependent, the type of complaint that the patient presents may be selected at random from a distribution that reflects the actual historical experience with patients, and the service time for each procedure that the patient undergoes could be modelled by an exponential or a gamma distribution (for example). Random numbers generated from these distributions move transactions through the system until either they are discharged or admitted to the hospital's general population. For an introduction to discrete-event simulation methods see Banks et al. [19].

Because discrete event simulations are driven internally by random forces, they produce an output response that is a random variable. Consequently, the full range of standard experimental design methods, including factorial and fractional factorial designs and response surface designs, can be applied to these models. Hunter and Naylor [20] illustrate the uses of factorial, fractional factorial, and response surface designs in the context of two computer simulation models and provide a brief discussion about the pitfalls associate with computer simulation experiments.

Some practical problems that arise when experimenting on computer simulations include sample size determination, the issue of multiple responses, and the problem of non-linearity. Additional issues that are unique to computer simulation models include how to choose the simulation run length and the duration of the warm-up period (if any is required). See Law [21] for a discussion of these and other related issues. Also, if replication is used, it is usually standard practice to use a different stream of random numbers (or a different random number generator seed) for each replicate, so that replicates can be taken as blocks to reduce some of the variability in the model output.

Many discrete-event simulations have a large number of input variables. Depending on the simulation run length in real time there can be situations where the number of factors renders the use of conventional fractional factorial designs problematic. Supersaturated designs, which have fewer runs than the number of factors, can prove useful in these situations. Lin [22] is a useful reference on construction of supersaturated designs. Forward stepwise regression can be used to analyse the data from a supersaturated design. See Holcomb et al. [23] for a discussion of other design construction and analysis methods. In some simulations there can be input variables that can be treated as noise variables. For example, in the hospital emergency department, the analyst may want to treat the patient arrival rate as a noise factor because it cannot be controlled in practice by the management of the emergency department, and it may be desirable to try to find settings of the factors that can be controlled that work well across a wide range of arrival patterns. Designs that incorporate noise factors and methods for analysing these designs to minimize the variability transmitted from the noise factors are discussed in Myers et al. [24].

Simulation models can present other challenges for the experimental designer. Often the output response cannot be summarized by a single summary statistic or group of summary statistics. Common situations are time series output or functional output, in which one response is related to one or more other responses through a functional relationship. In many case the output response may be poorly modelled by a normal distribution. For example, in the hospital emergency room simulation the patient waiting times may follow a gamma distribution. Since the gamma distribution is a member of the exponential family, generalized linear models may be useful in the analysis of these types of response. For examples of using generalized linear models to analyse data from designed experiments see Lewis et al. [25] and Myers et al. [26]. If the experimenter knows or suspects in advance that the response is an exponential family member, it is possible to design an experiment based on the $D$-optimality criterion, which is more appropriate than classical designs. This is discussed in Johnson and Montgomery [27] and Myers et al. [26].

\section{DESIGN OF EXPERIMENTS: CASE EXAMPLES FROM THE NON-MANUFACTURING SERVICE INDUSTRY}

\subsection{Data entry errors}

The Prescription Pricing Authority (PPA) is responsible for processing all prescriptions issued by medical doctors and dispensed by pharmacies throughout England. About 500 million prescriptions per annum are processed by nearly 1000 staff. With a general rise in competition to supply such a service, there is a constant need to update and improve efficiency.

There are two main aims of the working process, to input data accurately and quickly. It had long been 
Table 5 Experimental design for data entry experiment

\begin{tabular}{lll}
\hline Staff ID & Experience & Instruction \\
\hline A & Novice & Go fast \\
B & Semi-experienced & Go fast \\
C & Experienced & Go fast \\
D & Semi-experienced & Be accurate \\
E & Novice & Be accurate \\
F & Experienced & Be accurate \\
G & Experienced & Do both \\
H & Semi-experienced & Do both \\
I & Novice & Do both \\
\hline
\end{tabular}

thought that asking staff to work as quickly as possible compromises accuracy levels; as input speeds become more rapid less care would be taken or fewer self-checks would be performed.

It was decided to run an experiment with two threelevel factors:

- Staff factor: experienced, semi-experienced, and novice.

- Instructions factor: 'go as fast as you can', 'be as accurate as possible', and 'go as fast as you can and be as accurate as possible'.

Thus, it would be discovered if particular instructions produced different effects in relation to different experience levels (Stewardson et al. [28]). The experimental design is shown in Table 5.

Three staff were chosen in each of the categories, Experienced, Semi-experienced, and Novice. One person from each experience level was instructed to 'go as fast as you can', another was told to 'be as accurate as possible' and the third was told to do both. The trial lasted for five days, during which time staff input basic prescription details over a number of batches of prescriptions. There were two measurable outputs, speed (the number of inputs per hour averaged over a day) and accuracy (proportion of inputs with an error). Input speeds increased over the five days and the response variables were considered as they changed over time, as well as just as an average. Accuracy rates tended to remain fairly constant over this short period of time. It was also clear that there is no obvious connection between speed and accuracy. Differences in the outcomes were attributed to the specific instructions and experience levels.

The trials proved a resounding success, with good cooperation being obtained from all staff. The experiment established that the speed of input was the critical item that needed to be included in working instructions. Accuracy is affected by the experience level. If a person is asked to 'go fast', it will not tend to affect their accuracy level, but if they are asked to be accurate, speed will reduce, without any noticeable effect on accuracy. It is thus favourable to insist on faster speeds and accuracy levels will, apparently, hold their 'natural' level. This is just one example of the use of a designed experiment involving human performance.

The key benefits of this designed experiment were that it showed the effect of issuing different types of commands on the speed and accuracy of data entry as well as evaluating the differences in performance between different types of staff. It also led to the establishment of a minimum expected performance standard for novices, which helped determine recruitment and training needs. The experiment also allowed an assessment of the level of variation in data entry speed and accuracy between people.

Managerial implications were that a scientific approach could be applied to the assessment of performance. Statistical process control using cusum charts was also implemented for the data entry process and proved to be a workable methodology for deciding when bonuses should be given and when re-training was needed.

Lessons learnt included that a range of statistical techniques could be used in the context of the PPA, which is effectively an enormous data processing plant. Many quality improvement initiatives were also carried out and random sampling and statistical modelling were widely employed in a cross-departmental acceptance of the importance of the quantitative approach. More recently extensive data mining has been undertaken to examine changes in the pattern of prescriptions over time as regards their value, content, source, and mix, with the aim of providing a foundation for process improvement.

\subsection{Debt collection}

Slow payment of invoices is a big problem and is particularly difficult for smaller companies. A continuous improvement project at a local SME (small- or medium-sized enterprise) looked at the performance of the whole flow of the company from receipt of orders to receipt of payment (Coleman et al. [29]).

In common with many companies, the manufacturing plant had been intensely modernized and was working very efficiently. Payment of invoices, however, was very slow and variable between customers. To help improve this situation, data were collected and analysed. It was found that the Pareto principle applied, with most customers paying within a reasonable time and some delaying unacceptably.

The ideas of experimental design were discussed at a problem-solving team meeting. It was decided to 
Table 6 Experimental design for debt collection experiment

\begin{tabular}{lllr}
\hline Contact regime & Written contact & Phone contact & Timing \\
\hline A & No letter & No phone & 10 days \\
B & Letter & No phone & 10 days \\
C & No letter & Phone & 10 days \\
D & Letter & Phone & 10 days \\
E & No letter & No phone & 30 days \\
F & Letter & No phone & 30 days \\
G & No letter & Phone & 30 days \\
H & Letter & Phone & 30 days \\
\hline
\end{tabular}

see which factors would help speed up the payment of bills. It was noted from experience that it was better to phone after $2 \mathrm{pm}$ and to avoid phoning on Fridays. The aim was to try to find the optimum strategy and improve the time to payment of bills.

Three two-level factors were chosen for the designed experiment:

- Written contact: send or do not send a letter.

- Phone contact: phone or do not phone.

- Timing of contact: 10 days after sending invoice or 30 days.

Eight trials were planned with different contact regimes. The experimental design is shown in Table 6 .

The debtor companies were randomly assigned to one of the eight trials. They were dealt with according to the experimental design and the time before payment was recorded. The outcome variable was the time to payment. It was found that sending a letter and telephoning 10 days after sending the invoice was by far the best strategy.

Applying this new strategy over the next few months, the time to wait for payment of bills was significantly reduced. Overall, the time from enquiry to payment was reduced from a mean of 110 days to a mean of 85 days. This reduction of 25 days is a significant improvement and could make the difference between staying in business and going out of business.

The key benefits of this exercise were introducing staff to the concept of logical problem solving. There were also major benefits from the team activity of setting up the experiment, which involved identifying late payment as a problem, gathering information to quantify the problem, encouraging input from all the staff team, taking some action, and showing a useful result. Even if the results are not particularly surprising, the designed experiment has the advantage of making it possible to quantify the effect of the new strategy so that the cost of writing and phoning can be justified. There are several shortcomings in this experimental design, such as the skewed distribution of the measurable outcome, but, nevertheless, it shows that experiments can be useful in a service context. In this SME, designed experiments were used in the manufacturing plant and it was good for staff from all departments to share the methodology.

Managerial implications are that all staff can contribute to process improvement through quantitative analysis. The designed experiment provided more than just the measured outcome; an added bonus was that information was obtained as a result of the intervention and managers found out that many invoices were paid late because they were incorrect or had been lost in the post or had not been received for other reasons. The early intervention identified these problems so that they could be rectified.

Lessons learned are that it is possible to improve the payment of invoices. Recent contact with the company revealed that currently less than 1 per cent of invoices are being paid late, which is a marked improvement.

\subsection{Emergency department performance}

Kolker [30] describes a discrete-event simulation model of the patient flow in a hospital emergency department. Three metrics, percentage of ambulance diversion, number of patients in the waiting room, and upper limit length of stay (LOS), were used to characterize the performance of the studied ED. A baseline simulation model, which represented the historical performance of the ED, was validated through the three performance metrics.

The author identified two main phases of the ED simulation study. The goal in the first phase was to utilize simulation and experimental design to create a response model that could be used to predict the metrics, such as percentage of ambulance diversion, as a function of the LOS for patients admitted as inpatients and LOS for patients admitted as outpatients (home patients). The goal in the second phase of the study was to determine an optimal ED closure criterion. ED closure would allow the ED to temporarily divert ED ambulance drivers to other hospitals in order to reduce the size of the queue in the waiting room. A factorial design, with six levels of each factor was used to carry out the study in phase one. 
Both factors, LOS for patients admitted as inpatients and those admitted as outpatients, ranged from 5 to 24 hours. The specific levels for both factors tested in the factorial were $5,6,8,10,12$, and 24 hours.

Results of the experimentation performed on the simulation provided quantitative measures of the performance characteristics of the ED. Response surface modelling illustrated that the percentage of ambulance diversions was negligible when LOS was less than 6 and 5 hours for inpatient and home patient visits respectively. The ED closure criterion was when the number of patients in the queue was 11 . Through the modelling of the ED department and use of historical data to drive the inputs, Kolker demonstrated how experimental design was beneficial in the context of analysis of the current system and the how to use findings of the study to influence management decisions.

\section{CONCLUSION}

Design of Experiments has been widely applied to quality- and process-related problems in manufacturing organizations. However, research has indicated that very little attention has been given to the application of DoE in the context of non-manufacturing or service processes. This paper attempts to demonstrate the power of DoE in a nonmanufacturing/service environment. The benefits and challenges in the application of DoE in the context of non-manufacturing/service processes are presented and viewpoints from a number of practitioners and academics on the benefits and challenges are also highlighted. The paper also describes three simple case examples to illustrate the application of this powerful technique in non-manufacturing/service settings. The authors believe that DoE has tremendous potential but is greatly underutilized in non-manufacturing/service organizations. We also expect to see more applications of DoE in non-manufacturing or service industries in the next 5 to 10 years or so because of the increased use of Six Sigma methodologies in the sector.

(C) Authors 2011

\section{REFERENCES}

1 Montgomery, D. C. Design and analysis of experiments, 7th edition, 2009 (John Wiley \& Sons, Inc., Hoboken, New Jersey).

2 Antony, J. Some key things industrial engineers should know about experimental design. Logistics Inf. Managmt., 1998, 11 (6), 386-392.
3 Shainin, D. and Shainin, P. Better than Taguchi orthogonal tables. Quality and Reliability Engng Int., 1988, 4(2), 143-149.

4 Johnson, L., and Bell, G. Designed experiments in service quality applications. In World Congress on Quality and improvement, ASQ Conference, May 2009, 18-20, Minneapolis, Minnesota, USA.

5 Kapadia, M. and Krishnamoorthy, S. A methodology of enhancing profitability through the utilization of experimental design: a catering business case study. Total Quality Managmt., 1999, 10(7), 1027-1036.

6 Ledolter, J. and Swersey, A. Using a fractional factorial design to increase direct mail response at Mother Jones magazine Quality Engineering, 2006, 18, 469-475.

7 Blosch, M. and Antony, J. Managing service quality. Managing Service Quality, 1999, 9(5), 311-319.

8 Kumar, A., Motwani, J., and Otero, L. An application of Taguchi's robust experimental design technique to improve service performance. Int. J. Quality and Reliability Managmt., 1996, 13(4), 85-98.

9 Roes, K. C. B. and Dorr, D. Implementing statistical process control in service processes. Int. J. Quality Sci., 1997, 2(3), 149-166.

10 Raajpoot, N., Javed, R., and Koh, K. Application of Taguchi design to retail service. Int. J. Commerce and Managmt., 2008, 18(2), 184-199.

11 Holcomb, M. C. Customer service measurement: a methodology for increasing customer value through utilisation of the Taguchi strategy. J. Business Logistics, 1994, 15(1), 29-52.

12 Goh, T. N. The role of statistical design of experiments in Six Sigma: perspectives of a practitioner. Quality Engng., 2002, 14(4), 659-671.

13 Holland, C. W., and Cravens, D. W. Fractional factorial designs in marketing research. J. Marketing Res., 1973, 11, 286-294; http://www.cmqr.rmit. edu.au/7icit.html.

14 Starkey, M. Extending process thinking: experiments in sales and marketing. The TQM Mag., 1997, 9(6), 434-439.

15 Anderson, M. J. Achieving breakthroughs in nonManufacturing processes via DoE, Stat-Ease (accessed from Stat-Ease website in July 2009; www.statease.com).

16 Garcia, M., Centeno, M., Rivera, C., and DeCario, N. Reducing time in an emergency room via a fasttrack. In Proceedings of the 1995 Winter Simulation Conference, 1995, pp. 1048-1053.

17 Miller, M., Ferrin, D., and Szymanski, J. Simulating Six Sigma improvement ideas for a hospital emergency department. In Proceedings of the 2003 Winter Simulation Conference, 2003, pp. 1926-1929.

18 Simon, S., and Armel, W. The use of simulation to reduce the length of stay in an emergency department. In Proceedings of the 2003 Winter Simulation Conference, 2003, pp. 1907-1911.

19 Banks, J., Carson, J. S., Nelson, B. L., and Nicol, D. M. Discrete-event system simulation, 4th edition, 2005 (Prentice-Hall, Upper Saddle River, New Jersey). 
20 Hunter, J. S. and Naylor, T. H. Experimental designs for computer simulation experiments. Management Science, 1970, 16(7), 422-434.

21 Law, A. M. Statistical analysis of simulation output data: the practical state of the art. In Proceedings of the 39th Winter Simulation Conference, Washington, DC, 2007, pp. 77-83.

22 Lin, D. K. J. Recent developments in supersaturated designs. In Statistical process monitoring and optimization, chapter 18 (Eds S. H. Park, G. G. Vining), 2000, pp. 305-319 (Marcel Dekker, New York).

23 Holcomb, D. R., Montgomery, D. C., and Carlyle, W. M. Analysis of supersaturated designs. J. Quality Technol., 2003, 35(1), 13-27.

24 Myers, R. H., Montgomery, D. C., and AndersonCook, C. M. Response surface methodology: process and product optimization using designed experiments, 3rd edition, 2009 (John Wiley \& Sons, Inc., Hoboken, New Jersey).

25 Lewis, S. L., Montgomery, D. C., and Myers, R. H. Examples of designed experiments with nonnormal responses. J. Quality Technol., 2001, 33(3), 265-278.
26 Myers, R. H., Montgomery, D. C., Vining, G. G., and Robinson, T. J. Generalized linear models with applications in engineering and the sciences, 2nd edition, 2010 (John Wiley \& Sons, Inc, Hoboken, New Jersey).

27 Johnson, R. T. and Montgomery, D. C. Choice of second-order response surface designs for logistic and Poisson regression models. Int. J. Expl Des. and Process Optimization, 2009, 1(1), 2-23.

28 Stewardson, D. J., Linsley, M. J., Alexander, B., and Hebron, D. Using designed experiments in HRM: determining achievable working standards in a redesigned data-input process. In 7th International Conference on ISO 9000 \& TQM (ICIT), RMIT University, Melbourne, 2-4 April 2002.

29 Coleman, S. Y., Francis, J., Hodgson, C., and Stewardson, D. J. Helping smaller manufacturers implement performance measurement. Industry and Higher Education, 2001, 15(6), 409-414.

30 Kolker, A. Process modeling of emergency department patient flow: effect of patient length of stay on ED diversion. J. Med. Systems, 2008, 32, 389-401. 